\title{
Research on the Design of College Smart Classroom Teaching Mode under the Background of "Internet +"
}

\author{
Yue Wang \\ Jilin Engineering Normal University \\ $51386781 @ q q . c o m$
}

Keywords: Internet +; Colleges; Smart classroom; Teaching mode

\begin{abstract}
Wisdom classroom is a hot spot in the current educational informationization research, and it is the product of the deep integration of new technology and education. The smart classroom created by the new generation of information technology can track the whole process before, during and after class. It is also the inevitable result of school education informatization focusing on classroom teaching, focusing on teacher and student activities, and focusing on wisdom generation under the background of Internet + education. This paper designs a smart classroom teaching model that is in line with the development of the times and is used to guide specific teaching practices. The purpose of this paper is to explore whether the new teaching model can stimulate students' interest in learning and improve their ability to learn intelligently.
\end{abstract}

\section{Introduction}

Since 2010, China has entered the era of intelligent interconnection and data technology. In this era, people have become accustomed to and rely on the use of mobile information to acquire knowledge along with the rapid development of digital culture. People can access all aspects of the knowledge through the Internet anytime, anywhere. The era of smart internet, mobile information, and digital economy is affecting and changing people's lifestyles and learning styles[1]. Especially the college students born in 1995, they are influenced by the Internet, smart phones, tablets and other scientific and technological products, and some people call this generation $\mathrm{Z}$ generation. This generation of students enjoys acquiring knowledge through information tools such as apps, laptops, and tablets, both in class and after class. This change in learning style has led to the reform of traditional teaching. Therefore, in the context of intelligent interconnection, we need to change the traditional teaching of teaching into a combination of information and classroom teaching. Designing the teaching mode of college smart classroom under the background of "Internet +".

American Joyce and Will are the first educators to propose the word teaching mode. According to their teaching model theory, they draw the elements of the intelligent classroom teaching model, including the theoretical basis, the realization conditions, the wisdom teaching objectives, the wisdom teaching activities and Wisdom teaching evaluation.

\section{Building a Smart Classroom Teaching Model}

The core model is built around the realization of conditions, smart teaching objectives, smart teaching activities and smart teaching evaluation[2], as shown in Figure 1-1. 


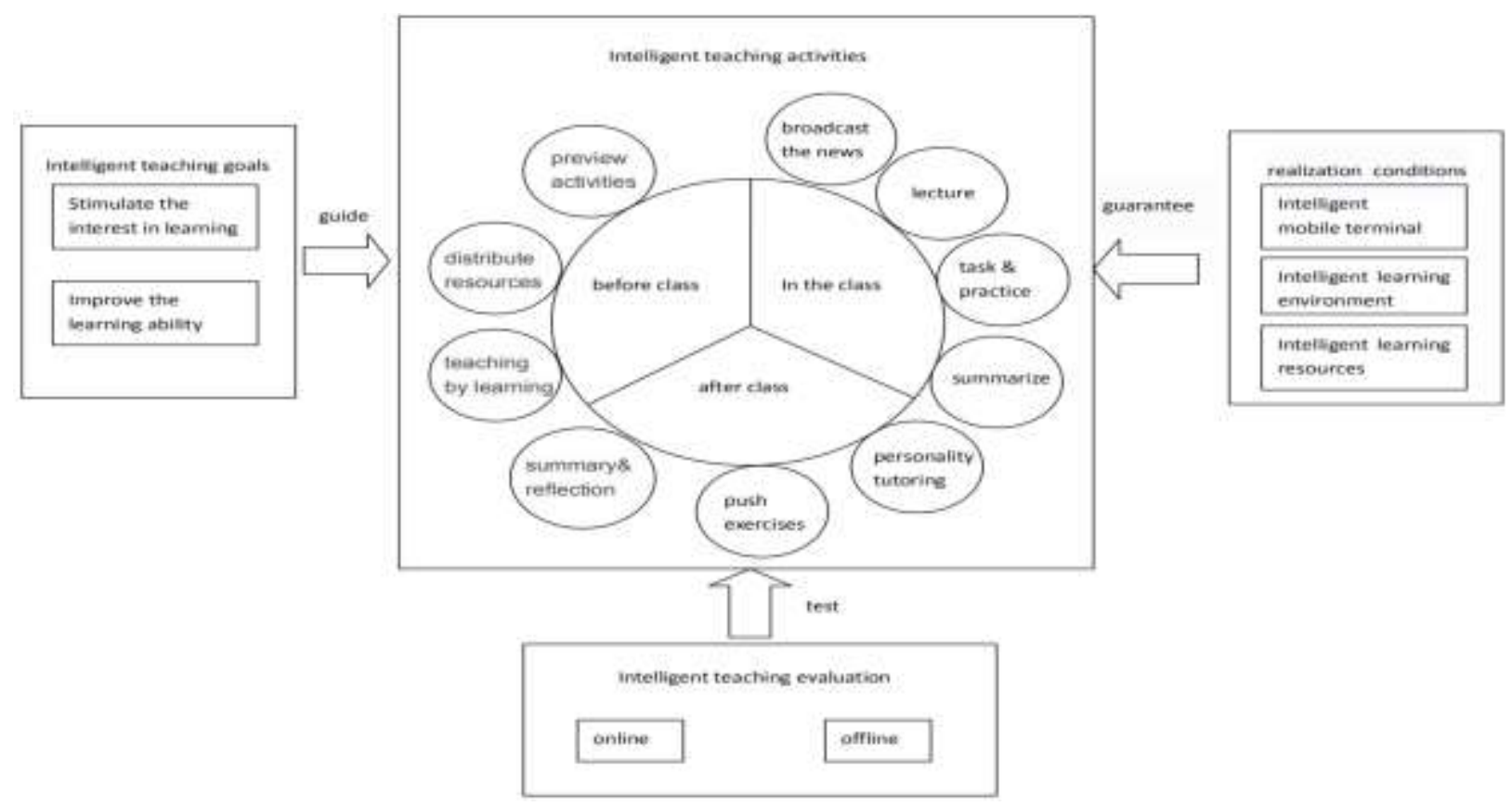

1-1 Building a smart classroom teaching model

\section{Realization Conditions}

Intelligent mobile terminal. With the development of mobile internet technology, mobile learning has gradually become an indispensable learning mode for modern people[3]. Along with this is the emergence of mobile learning devices that support learners to learn autonomously at any time, anywhere.

The smart mobile terminal in the smart classroom teaching mode refers to the smart phone, which has invaluable use in the field of education, mainly summarized as follows: (1) social function. Smartphones can be used not only to send and receive messages, but also to communicate via chat tools such as WeChat and QQ. (2) Search query function. Students encounter problems in the process of learning. Smartphones can query information anytime and anywhere, and solve doubts in time. (3) Educational applications. There are endless applications of education, such as time management, various types of research, language learning, subject learning, video open classes, and development of intelligence. (4) Photo recording function. (5) Read the viewing function.

Smart Learning Environment. The learning environment includes a physical learning environment and a virtual learning environment. The physical environment for classroom learning is mainly the classroom environment[4]. The physical environment of the smart classroom teaching model is a smart classroom, and the virtual environment refers to a smart learning platform. The following describes the environmental support of the smart classroom teaching mode through two aspects: smart classroom and smart learning platform:

The physical environment that the smart classroom relies on is the smart classroom. The ideal smart classroom is composed of infrastructure, ubiquitous network, teaching platform, technical support platform, mobile terminal equipment and so on. The infrastructure includes tables and chairs benches, lights, projections, computers, speakers, cameras, wireless routers, etc. The ubiquitous network provides a variety of network connections, such as $4 \mathrm{G}$, Wi Fi, etc. The technical support platform includes data collection and storage in the analysis platform, teaching The platform includes a teaching implementation platform and a teaching management platform, and the mobile terminal device has a smart phone and a tablet computer.

With the advent of the "Internet +" era, many open, personalized, and intelligent mobile learning platforms have emerged, and the functions of the platform have been continuously improved. Set-up, release tasks, teacher-student interaction, assignment distribution, voting, and teaching evaluation. And other functions as one. These platforms are recognized and applied by the 
community. For example: Rain Class, Nearpod, Micro Assistant, Class, Cladd Dojo, Showbie, Blue Ink Class, Super Star Learning, etc.

Smart Learning Resources. Learning resources refer to the information resources and physical media needed in the process of teaching activities, which is the basis for teaching and learning activities between teachers and students. Information resources are collections of information activities such as information technology, equipment and facilities, and information producers. Physical media refers to the physical objects, specimens, models and other teaching aids used in the learning process[5]. It has the characteristics of visualization and visualization, and has a sense of realism, space and stereo.

Smart learning resources are the resources needed to support smart classroom teaching, with features such as intelligent push, context awareness, and rich media. The learning resources supported by the online learning platform are divided into preset learning resources and generative learning resources[6]. The preset learning resources are that the learners can access the resource library anytime and anywhere through the terminal device, and select according to their own interests and interests. The cloud platform can also push resources on demand by analyzing learner characteristics. The generative learning resource is the resource continuously generated by the learner in the learning activity. The learner records the interaction process with the peers in the learning community, the individual reflection of the learner after the learning activity, and some result entity, online testing. Results and so on are all categories of generative resources[7].

\section{Wisdom Teaching Objectives}

The teaching goal exists before the teaching activities, and it is a concept and expectation of the teaching workers on the results of the teaching activities. The ultimate goal of the goal of wisdom teaching is to promote the generation of students' wisdom through smart classroom teaching, to stimulate students' interest in learning, and to improve the ability of learning and learning wisdom. The discussion about the goal of wisdom teaching is divided into three parts, the general goal, the three-dimensional goal and the specific goal. The relationship between them is shown in Table 3-1.

3-1 Smart teaching goal

\begin{tabular}{|c|l|c|}
\hline \multicolumn{2}{|c|}{ Smart teaching goal } \\
\hline main target & teaching objectives & Three-dimensional target \\
\hline Cultivate smart students & Course objectives & Knowledge and skills \\
Stimulateinterestinlearning & Unit goal & $\begin{array}{l}\text { Process and method } \\
\text { Emotions and values } \\
\text { Improve intelligence }\end{array}$ \\
& Class goal & \\
\hline
\end{tabular}

\section{Wisdom Teaching Activities}

The intelligent classroom teaching activities are divided into three parts: pre-class, in-class and after-class. Each part is composed of teacher activities and student activities. The details are as follows.

Before class.In the design process of the pre-class preparation activities, the teacher should design the pre-study content according to the specific learning objectives and the results of the student characteristics analysis, prepare the pre-study materials, and provide the expanded resources for the students' pre-school preparation activities[8]. After the teacher designs the teaching activities, the students are pushed to the students through mobile devices, and the students start learning before class.

Online communication students can express their opinions on the pre-study materials shared by teachers, such as where there are mistakes or inappropriate places, or recommend the materials that they think are better. For the problems encountered in the preview process, the study can communicate with the teacher on the learning platform, ask questions or opinions, the teacher gives a preliminary explanation, and adjust the teaching content. You can also give advice to the teacher and design teaching activities from the perspective of the students. Teachers can adopt 
corresponding strategies to encourage students to exchange and enhance the feelings of teachers and students.

The teaching program teachers carry out comprehensive analysis based on the students' pre-study situation, the answering situation and the communication situation, and modify and optimize the teaching design plan.

In class. The key to smart classroom teaching lies in classroom interaction, and its core is the three-dimensional interactive process. In the process of teaching, the main position of the students is emphasized, and the teachers play the role of guides and promoters.

The news broadcast is to let students use the team's first 8-10 minutes (including the comment time) to divide the teaching class into several groups, and to broadcast the news of each group's homemade PPT format. Then the teacher analyzes and develops the news and professional related knowledge, and uses professional knowledge to explain the news phenomenon. The collection of news, production, and broadcast is the result of the joint efforts of each team member of this team.

The course explains that teachers can create learning scenarios and import teaching content in a variety of ways[9]. Since the students have already preliminarily studied the content of the course before the class, the teacher can introduce new lessons in the form of preview feedback, test exercises and so on. Explain and interpret the content of the new lesson.

After the new task of the task is explained, the teacher enters the stage practice stage. The teacher releases the new learning task through the mobile device in his hand, and organizes and guides the group to carry out cooperation and inquiry learning.

Raise students' ability to analyze and solve problems.

Inductively summarizing and consolidating the internalization teachers to comment on the work of each group based on the feedback results, compare and analyze the learning results of each group, in the process of teacher comments, the exchanges between teachers and students are further deepened, and the groups learn from each other. It is conducive to cultivating students' critical thinking and promoting the meaning construction of students' knowledge.

After class. In the after-school stage, through the smart learning platform, teachers can push personalized review resources for individual student differences and publish targeted after-school exercises. The student submits the homework after the homework is completed within a certain period of time, and the teacher's platform will receive the student's answer. This kind of personalized counseling is more efficient, intuitive and fast. Students can view the work situation in time, communicate with the teacher online, correct the homework, and summarize and reflect.

\section{Wisdom Teaching Evaluation}

Teaching evaluation regarded as a feedback adjustment mechanism of the entire learning system, playing an important role in the learning process.

The evaluation thought of the wisdom teaching evaluation is based on the students' "learning" to evaluate the teacher's "teaching", that is, the idea of teaching and learning. The main body of the evaluation is the students. In the smart classroom teaching mode, the students' learning is divided into extracurricular and in-class, and the extracurricular is mainly online learning. The lesson is mainly offline classroom learning.

Online evaluation. Online evaluation is a process in which students use their smartphones to learn online. They will leave a lot of data about learning behaviors, learning preferences, learning habits, etc. These data can be said to be the information assets of each student[10]. The behavioral data recorded by the learning platform is an important basis for online learning evaluation.

Offline evaluation. Offline evaluation refers to a series of evaluations of students' learning behavior in the physical classroom. Classroom teaching is based on the traditional classroom environment, including teacher lectures, problem exploration, group cooperation to solve problems, display results, teacher reviews and other series of learning activities. Offline evaluation is an important part of the teaching evaluation based on the wisdom classroom, which mainly includes the students' classroom learning status, self-evaluation and learning outcomes. The learning state is embodied in the communication state, emotional state, attention state, thinking state and result state 
of the students in the classroom. Self-evaluation refers to the objective evaluation of your own learning process. Learning outcomes include work completed by students, assignments, and test results.

\section{Acknowledgement}

Supported by Key Projects of Jilin Educational Science Planning Research (Project Title: Design and application of intelligent classroom teaching mode in universities under the background of "Internet+", Contract No.ZD18094)

\section{References}

[1] Ali Research Institute "Internet +" Research Report [R/OL]http://www.askci.com/chanye/2015/03/13/85637vPqv.shtml. 2015-03-13.

[2] Bruce Joyce, Martha Weir, Emily Calhoun. Teaching Model (Seventh Edition) [M]. Beijing: Renmin University of China Press, 2014.

[3] Bi Wei. Challenges and Countermeasures of College Teachers' Professional Ability under the Background of "Internet + Classroom"[J]. Modern Education Management, 2015, (12): 5.-55.

[4] Zhai Jinjin, Xu Fuyin. Research on the design and effect of learning mode based on smart classroom[J]. China Electro-education Education, 2016, (2): 64-68.

[5] Chen Li, Lin Shiren, Zheng Qinhua. Opportunities and Challenges of Distance Education in China in the Age of "Internet +"[J]. Modern Distance Education Research, 2016, (1): 3-10.

[6] Cui Zhiwei. Going to multi-dimensional governance: the teaching reform of "interconnected network + classroom" [J]. School Management, 2016, (7): 11-13.

[7] Chen Kang, Zhu Yanping, Luo Wei. Research on the Design of Inverted Classroom Teaching under the Background of "Internet +"—-Taking International Business Documentary Classroom Teaching as an Example[J]. Foreign Trade and Economics, 2016, (7): 153-155.

[8] Guo Xiaoshan, Zheng Xudong, Yang Xianmin. Conceptual Framework and Pattern Design of Smart Learning[J]. Modern Educational Technology, 2014, (8): 5-12.

[9] He Kekang, Lin Junfen, Zhang Wenlan. Teaching System Design [M]. Beijing: Higher Education Press, 2006: 81.

[10] Huang Ronghuai. The Three Realms of Wisdom Education: From Environment, Model to System [J]. Modern Distance Education Research, 2014, (6). 